\title{
Diarrhea management in children under five in sub-Saharan Africa: does the source of care matter? A Countdown analysis
}

Liliana Carvajal-Vélez ${ }^{*}$, Agbessi Amouzou', Jamie Perin², Abdoulaye Maïga ${ }^{3}$, Hayalnesh Tarekegn', Akanni Akinyemi ${ }^{4}$, Solomon Shiferaw ${ }^{5}$, Mark Young ${ }^{1}$, Jennifer Bryce ${ }^{2}$ and Holly Newby ${ }^{1}$

\begin{abstract}
Background: Diarrhea remains a high burden disease, responsible for nine percent of deaths in children under five globally. We analyzed diarrhea management practices in young children and their association with the source of care.

Methods: We used Demographic and Health Survey data from 12 countries in sub-Saharan Africa with high burdens of childhood diarrhea. We classified the quality of diarrhea management practices as good, fair, or poor based on mothers' reports for children with diarrhea, using WHO/UNICEF recommendations for appropriate treatment. We described the prevalence of diarrhea management by type and assessed the association between good management and source of care, adjusting for potential confounders.

Results: Prevalence of good diarrhea management is low in 11 of the 12 analyzed surveys, varying from $17 \%$ in Cote d'Ivoire to $38 \%$ in Niger. The exception is Sierra Leone, where prevalence of good practice is $67 \%$. Prevalence of good management was low even among children taken to health facilities [median $52 \%$, range: 34-64\%]. Diarrhea careseeking from health facilities or community providers was associated with higher odds of good management than care from traditional/informal sources or no care. Careseeking from facilities did not result systematically in a higher likelihood of good diarrhea management than care from community providers. The odds of good diarrhea management were similar for community versus facility providers in six countries, higher in community than facility providers in two countries, and higher in facility than in community providers in four countries.

Conclusion: Many children's lives can be saved with correct management of childhood diarrhea. Too many children are not receiving adequate care for diarrhea in high-burden sub-Saharan African countries, even among those seen in health facilities. Redoubling efforts to increase careseeking and improve quality of care for childhood diarrhea in both health facilities and at community level is an urgent priority.
\end{abstract}

Keywords: Child health, Diarrhea, Household surveys, Health providers, Oral rehydration salts

Abbreviations: DHS, Demographic and Health Survey; DRC, Democratic Republic of the Congo; MICS, Multiple Indicator Cluster Surveys; ORS, Oral Rehydration Salts; UNICEF, United Nations Children's Fund; WHO, World Health Organization

\footnotetext{
* Correspondence: liliana.carvajal.a@gmail.com

'United Nations Children's Fund UNICEF, 3 UN Plaza, New York City, NY

10017, USA

Full list of author information is available at the end of the article
}

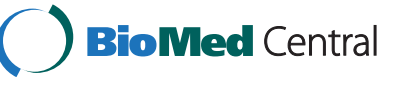

(c) 2016 The Author(s). Open Access This article is distributed under the terms of the Creative Commons Attribution 4.0 International License (http://creativecommons.org/licenses/by/4.0/), which permits unrestricted use, distribution, and reproduction in any medium, provided you give appropriate credit to the original author(s) and the source, provide a link to the Creative Commons license, and indicate if changes were made. The Creative Commons Public Domain Dedication waiver (http://creativecommons.org/publicdomain/zero/1.0/) applies to the data made available in this article, unless otherwise stated. 


\section{Background}

Diarrheal disease is highly preventable, yet accounts for nine percent of all deaths among children under age five worldwide [12]. In 2013, this translated into about 580,000 child deaths, or, on average, 1,600 children dying each day due to preventable diarrhea [21]. Most deaths from diarrhea occur among children less than 2 years of age living in South Asia and subSaharan Africa [9]. In 2004, WHO and UNICEF issued a joint statement on clinical treatment of acute diarrhea, recommending the use of low-osmolarity oral rehydration salts (ORS), zinc supplementation, increased amounts of appropriate fluids, and continued feeding [22]. Treatment of diarrhea with ORS is a simple, proven, high-impact intervention that can be provided in home settings by caretakers or by health care providers at community and facility levels to prevent dehydration due to diarrhea and decrease related deaths. There is evidence that ORS may reduce diarrhea specific mortality by up to $93 \%$ [15]. However, data analysis from recent population-based household surveys show that population coverage for this basic but effective intervention is still very low, particularly in countries that are hardest hit by diarrheal diseases. In sub-Saharan Africa, only about one in three children experiencing diarrheal episodes receives ORS, and the proportion receiving zinc is below $5 \%$ [19].

Although appropriate treatment of diarrhea is simple and can be done at home, seeking care from appropriate providers outside the home is recommended because harmful practices based on beliefs and misconceptions are prevalent, especially in low income countries where the diarrhea mortality is high. A systematic review of harmful practices in childhood diarrhea management found high and variable levels of harmful practices [3], such restriction of food and fluids, including breastfeeding. A recent analysis in six African countries found a high prevalence of fluid curtailment during episodes of diarrhea, and an association between seeking care outside of the home and higher rates of fluid curtailment, particularly for careseeking from non-government health providers [16]. Using an expanded set of countries, the current analysis investigates these findings further by assessing the prevalence of diarrhea management practices as defined in the 2004 WHO/UNICEF recommendations and their association with the source of care.

Recent studies have suggested that training publicsector providers to treat diarrhea in children with lowosmolarity ORS and zinc is effective in improving the quality of care [8]. But ensuring high and sustained implementation of appropriate treatment will require major investments in health worker training, supervision and other incentives to support correct health worker performance, as well as strategies to ensure the continuous availability of essential commodities such as ORS and zinc. Integrated community case management (iCCM) has been a pivotal strategy to reach vulnerable children and increase their chances of receiving appropriate care when sick with diarrhea or other pervasive illnesses like pneumonia and malaria.

This work was supported by [5] for Maternal, Newborn and Child Survival ("Countdown") with the goal of generating new information useful in increasing the effectiveness of programs aimed at reducing child deaths from diarrhea. Countdown is a global initiative that tracks progress in achieving high, sustained and equitable coverage for interventions of proven effectiveness in preventing unnecessary deaths among women and children in 75 priority countries [5].

\section{Methods \\ Data}

We selected twelve countries based on the following criteria: 1) being in sub-Saharan Africa given that it is the region with the greatest proportion of diarrhea deaths; 2) being high-burden: over $10 \%$ of country's deaths among children 1-59 months caused by diarrhea; and 3) having recent population-based survey data available (2010 or later) with sufficient sample size for analysis. We reviewed available nationally representative population data for countries meeting the above criteria from Demographic and Health Surveys (DHS) and Multiple Indicator Cluster Survey (MICS), but retained only DHS surveys because until 2013, MICS did not collect data on care seeking for childhood diarrhea which was a key variable for this analysis [20].

The 12 countries included in the analysis are: Burkina Faso (year of survey: 2010; \% deaths among 1-59 month-old caused by diarrhea in 2013: 14\%), Burundi (2010; $18 \%)$, Cameroon (2011; $16 \%)$, Cote d'Ivoire (2011-12; $15 \%)$, Democratic Republic of the Congo (DRC) (2013-14; $15 \%)$, Ethiopia (2011; $16 \%)$, Mali (2012-13; $16 \%)$, Niger (2012; $16 \%)$, Nigeria (2013; $14 \%)$, Sierra Leone (2013; $18 \%)$, United Republic of Tanzania (2010; $12 \%$ ), and Uganda (2011; $12 \%)$ [7, 21]. Together these countries accounted for about one-third of all under-five deaths worldwide due to diarrhea in 2013 and about two-thirds (62 \%) in sub-Saharan Africa [21]. Table 4 in the Appendix presents information about the evolution of the adoption and implementation of the low-osmolarity and zinc policy in sub-Saharan African countries as well as the number and percentage of childhood deaths caused by diarrhea.

DHS collects data on childhood diarrhea treatment from nationally representative samples. In the surveys, mothers are asked if their children under five had 
diarrhea in the past 2 weeks. If the answer is positive, they are asked follow-up questions about care seeking and treatment, including the four recommended management interventions (ORS, zinc, increased fluids, continued feeing) as well as other potentially harmful practices including antimotility drugs.

\section{Analysis}

We classified the quality of diarrhea management practice as good, fair, or poor based on the [22] guidelines (Table 1). We consulted with the Ministry of Health in each country to categorize the reported sources of care as facility, community based, traditional, or no care outside the home. Facility care refers to care sought from health facilities, whether public or private. Community-based care relates to care sought from community health workers, mobile clinics, village health posts, government dispensaries or health centers and health posts located at the community level, as well as pharmacies. Traditional sources of care include traditional healers, traditional practitioners as well as shops, stores, informal drug sellers and markets (Appendix Table 5). No care outside the home refers to children who were treated at home for diarrhea but for whom care was not sought outside the home.

'Good' diarrhea management is the main outcome of interest in this analysis, and source of care is the main independent variable. We first described prevalence of diarrhea management practices across countries, then examined the country specific unadjusted association between 'good' diarrhea management and type of care. We finally fitted logistic regression models of 'good' diarrhea management practice on source of care for all countries, adjusting for the following known confounders as described below. Table 6 in the Appendix presents the estimated regression coefficients (log odds ratios for adjusted factors) from logistic regression models for the factors from Anderson's conceptual framework, for the

Table 1 Classification of diarrhea management in children under-five into good, fair and poor based on WHO/UNICEF recommendations

\begin{tabular}{llll}
\hline Classification & $\begin{array}{l}\text { Child given ORS } \\
\text { or ORS or Zinc }\end{array}$ & $\begin{array}{l}\text { Child given } \\
\text { Increased Fluids (IF) }\end{array}$ & $\begin{array}{l}\text { Child Continued } \\
\text { Feeding (CF) }\end{array}$ \\
\hline Good & Yes & Yes & Yes \\
Good & Yes & Yes & No \\
Good & Yes & No & Yes \\
Fair & Yes & No & No \\
Fair $^{\text {a }}$ & No & Yes & Yes \\
Fair $^{\text {a }}$ & No & Yes & No \\
Poor & No & No & Yes \\
Poor & No & No & No
\end{tabular}

${ }^{\text {a } F o r ~ c h i l d r e n ~} 6$ months old and younger, defined as "good" practice probability of children under five receiving good diarrhea management.

We used Andersen's conceptual framework of access to medical care to help identify variables to control for in the regression model [1]. We identified these factors based on three main categories outlined in the Andersen' framework. The predisposing characteristics included child age, mother's age, child gender, mother's marital status and education, partner's education, parity, number of children under five living in the household; the enabling resources included wealth quintile, rural or urban location, distance from health care reported by the mother as a problem in receiving health care, mother's participation in decision making, household improved water access, open defecation and the need characteristics included whether there was blood in the child's stool, as a measure of severity. However, all reported cases of diarrhea were included in the analysis and having had 'blood in stool' was not used for classification of diarrhoea but instead as a variable in the final regression model, thus avoiding potential misclassification issues. We assessed multicollinearity in these independent variables and retained only one of two or more variables that were highly correlated. The final model reported here includes adjustment for the following variables or potential confounders: child age, mother's age, child gender, mother's marital status and education, number of children under five living in household, wealth quintile, rural or urban location, if distance is a problem in receiving health care, mother's participation in decision making, whether household has improved water, and whether there was blood in the child's stool. These variables were all of the ones included in the initial Andersen's model, except for mother's participation in decision making and open defecation which were highly correlated with other variables and therefore not included in the final model. All regression analysis took into account the survey complex multi-stage sample design and sample weights. We used Stata 13 for analysis.

\section{Results}

Table 2 presents the proportion of children with diarrhea who were reported by their mothers to have been given any of the four recommended management interventions, as well as those who were reported to have been given both ORS and zinc. The number of household and women surveyed and response rates by country are presented in Table 7 in the Appendix. The results vary widely across countries. For example, coverage of ORS ranges from $17 \%$ in Cameroon and Cote d'Ivoire to $85 \%$ in Sierra Leone (median=38 \%). Across countries, coverage of zinc is extremely low (due to on-going roll-out of the policy for zinc in these 
Table 2 Percent of children with diarrhea in the 2 weeks prior to the survey by type of care reported by mothers and country

\begin{tabular}{|c|c|c|c|c|c|c|c|}
\hline \multirow[t]{2}{*}{ Country } & \multirow{2}{*}{$\begin{array}{l}\text { Weighted number } \\
\text { of Children }\end{array}$} & \multirow{2}{*}{$\begin{array}{l}\text { Weighted \# children } \\
\text { with diarrhea }\end{array}$} & \multicolumn{5}{|c|}{ Percentage of children with diarrhea in the last 2 weeks who were given } \\
\hline & & & $\begin{array}{l}\text { ORS \% } \\
(95 \% \mathrm{Cl})\end{array}$ & $\begin{array}{l}\text { ORS \& Zinc \% } \\
(95 \% \mathrm{Cl})\end{array}$ & $\begin{array}{l}\text { Zinc \% } \\
(95 \% \mathrm{Cl})\end{array}$ & $\begin{array}{l}\text { Increased Fluids \% } \\
(95 \% \mathrm{Cl})\end{array}$ & $\begin{array}{l}\text { Continued Feeding \% } \\
(95 \% \mathrm{Cl})\end{array}$ \\
\hline Burkina Faso & 14,001 & 2,064 & $21(19,24)$ & $0(0,0)$ & $0(0,1)$ & $26(23,29)$ & $79(77,82)$ \\
\hline Burundi & 7,418 & 1,855 & $38(35,41)$ & $0(0,0)$ & $0(0,0)$ & $40(37,43)$ & $72(70,75)$ \\
\hline Cameroon & 10,718 & 2,243 & $17(15,20)$ & $0(0,0)$ & $0(0,0)$ & $56(52,59)$ & $80(77,82)$ \\
\hline Cote d'Ivoire & 6,862 & 1,228 & $17(14,20)$ & $0(0,0)$ & $0(0,0)$ & $39(35,42)$ & $79(76,82)$ \\
\hline DR Congo & 16,968 & 2,852 & $39(36,42)$ & $2(1,2)$ & $2(2,3)$ & $32(29,36)$ & $71(68,75)$ \\
\hline Ethiopia & 11,042 & 1,483 & $26(23,30)$ & $0(0,0)$ & $0(0,0)$ & $16(12,19)$ & $60(56,65)$ \\
\hline Mali & 9,655 & 832 & $37(32,42)$ & $1(1,2)$ & $2(1,3)$ & $14(11,17)$ & $69(65,73)$ \\
\hline Niger & 12,268 & 1,734 & $44(41,47)$ & $8(7,10)$ & $10(8,12)$ & $24(21,28)$ & $73(70,77)$ \\
\hline Nigeria & 28,950 & 2,966 & $34(31,37)$ & $1(1,2)$ & $2(2,3)$ & $10(9,12)$ & $68(65,71)$ \\
\hline Sierra Leone & 10,814 & 1,201 & $85(83,87)$ & $3(2,5)$ & $4(3,5)$ & $32(27,37)$ & $64(61,68)$ \\
\hline Tanzania & 7,667 & 1,109 & $44(40,48)$ & $3(2,4)$ & $5(3,6)$ & $18(15,21)$ & $78(75,82)$ \\
\hline Uganda & 7,535 & 1,766 & $44(40,47)$ & $1(1,2)$ & $2(1,3)$ & $18(16,21)$ & $65(62,67)$ \\
\hline Median & 10,766 & 1,750 & $38(35,41)$ & $1(1,2)$ & $2(1,3)$ & $25(21,29)$ & $72(70,75)$ \\
\hline
\end{tabular}

countries), ranging from $0 \%$ in five out of the 12 countries to $10 \%$ in Niger (median $=2 \%$ ). The proportion of children who were reported to have been given increased fluids during diarrhea ranges from $10 \%$ in Nigeria to $56 \%$ in Cameroon (median $=25 \%$ ), and the proportion for whom mothers reported continued feeding the child during the diarrhea episode ranges from $60 \%$ in Ethiopia to $80 \%$ in Cameroon (median $=72 \%$ ). There are no systematic patterns suggesting any pairwise association between coverages of ORS, increased fluid and continued feeding.

Figure 1 presents the distribution of good, fair and poor diarrhea management practice by country. In 11 of the 12 countries, the prevalence of good diarrhea management practice was low, ranging from $17 \%$ in Cote d'Ivoire to $38 \%$ in Niger and Tanzania (median $=30 \%$ ). In Sierra Leone, the prevalence of good practice was $67 \%$. In contrast, levels of 'poor' diarrhea management are strikingly high across these countries with the exception of Sierra Leone (10 \%), with a prevalence of over $50 \%$ in 5 countries and ranging from 38 \% in Cameroon to 63 \% in Ethiopia (median $=48 \%)$.

Figure 2 and Table 8 in the Appendix present the result on the quality of diarrhea management by source of care. In all countries except Sierra Leone, mothers of children for whom care was sought outside the home were significantly more likely to report good diarrhea management than those for whom no care was sought outside the home. However, even among children with diarrhea taken to a health facility or community provider for care, the prevalence of 'good' management was low (median $=52 \%$, range $34 \%$ in Uganda to $64 \%$ in Sierra Leone). For those seen at the community level, the median prevalence of good management was $40 \%$ [range: $17 \%$ in Burundi to $72 \%$ in Sierra Leone], while for those taken to traditional care providers the median for good practice was $16 \%$ [range $6 \%$ in Burkina Faso to $67 \%$ in Sierra Leone]. In contrast, there is substantial 'poor' practice even for those taken to health facility or community care with a median prevalence of $28 \%$ and $36 \%$ for the two sources of care respectively.

Table 3 presents the adjusted odd-ratios of good diarrhea management practice by source of care. In general,

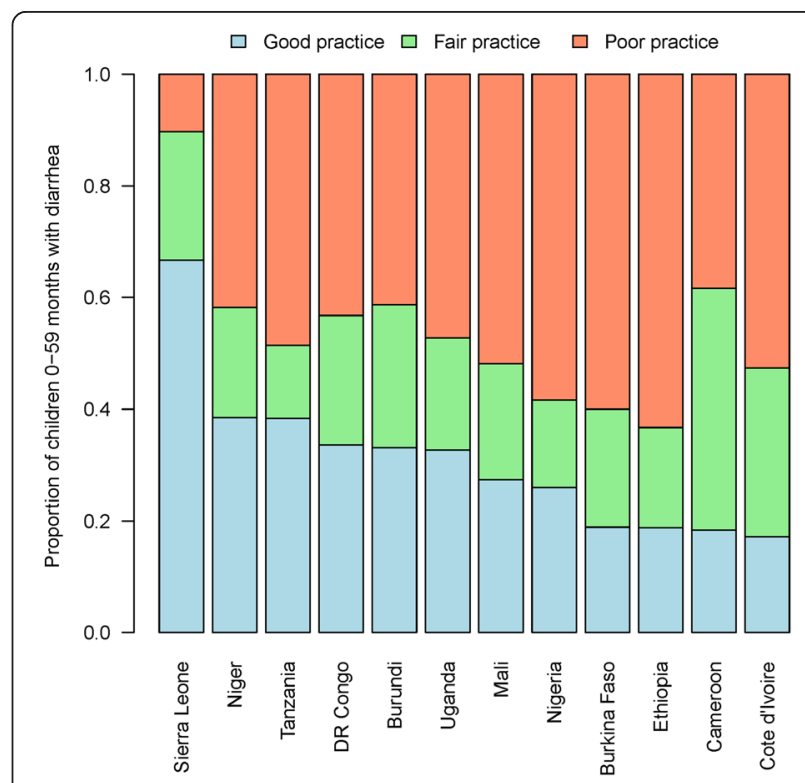

Fig. 1 Proportion of children under five with diarrhea in the 2 weeks prior to the survey by type of diarrhea management practice (good, fair or poor) 


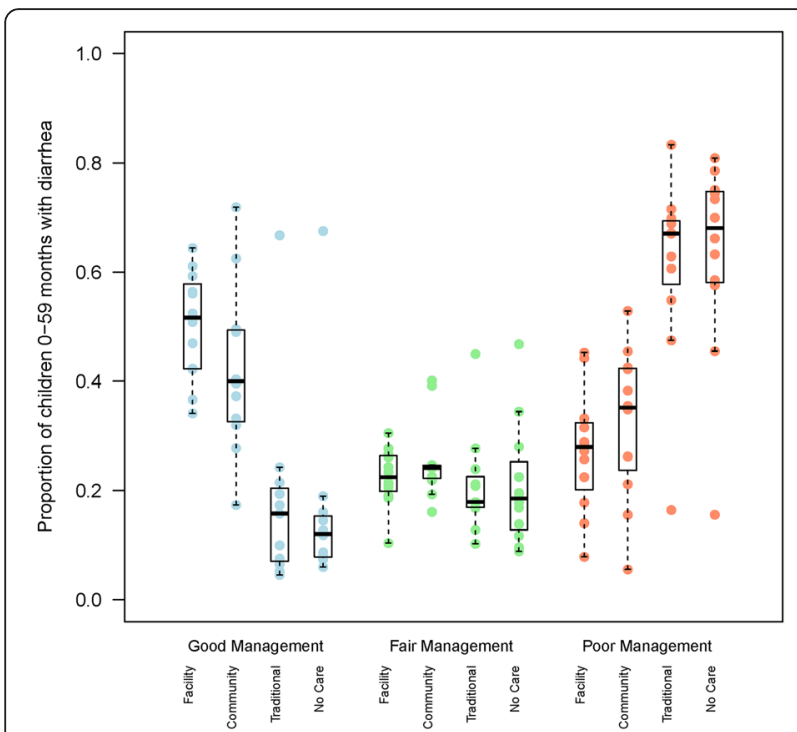

Fig. 2 Proportion of children under five with diarrhea in the 2 weeks prior to the survey by type of diarrhea management practice (good, fair or poor) and by source of care

as observed at bivariate level above, it suggests that sick children who were taken to health facility or community care were more likely to have had 'good' diarrhea management than children who were taken to traditional sources of care or not taken for care outside the home. In 11 of the 12 countries included in the analysis, mothers of children with diarrhea taken to health facility were 3.3 to 17 times more likely to have reported 'good' management for their condition than mothers of children not taken outside the home for care, after adjusting for selected confounders. This range was 1.4 to 13 for community care for the 12 countries. The exception is Sierra Leone, where 'good' management of diarrhea is high (over $60 \%$ ) regardless of place of care (Table 7 in the Appendix). In 4 countries, (Burkina Faso, Cote d'Ivoire, Nigeria, Sierra Leone) children taken for care to traditional providers are less likely to have 'good' management for their condition than children not taken anywhere for care. There is no statistically significant difference between traditional care and no care, except in Nigeria, where traditional care is more detrimental to children than no care. Table 3 presents the adjusted odds ratios and $95 \%$ confidence intervals for 'good' diarrhea management, and Table 9 in the Appendix present the unadjusted estimates.

A test for the interaction between child age and place of care indicates that the association between good diarrhea management and place of care was significantly less pronounced among children aged 0 to 5 months in seven of these eleven countries (Burkina Faso, Burundi, Cameroon, Cote d'Ivoire, DR Congo, Mali and Niger) than it is among older children. That is, older children with diarrhea taken to a health facility for care were given higher quality care than those who were not taken outside the home for care, but younger children taken to health facility were only slightly better managed than those with no care in these seven countries. However, children aged 0 to 5 months who were

Table 3 Adjusted odds ratios and $95 \%$ confidence intervals for good diarrhea management for enabling, predisposing, and need related factors per Anderson's model*

\begin{tabular}{llll}
\hline & \multicolumn{2}{l}{ Adjusted odds ratio and $95 \%$ confidence interval for good management (Reference: no care outside the home) } \\
\cline { 2 - 4 } & Facility Care & $5.7(4.0,8.2)^{*}$ & Traditional Care \\
\hline Burkina Faso & $12.0(8.0,18.2)^{*}$ & $2.2(0.9,5.3)$ & $0.7(0.3,1.8)$ \\
Burundi & $11.2(8.3,15.1)^{*}$ & $8.4(5.6,12.6)^{*}$ & $1.1(0.9,7.8)$ \\
Cameroon & $17.0(10.9,26.7)^{*}$ & $9.8)$ \\
Cote d'Ivoire & $9.6(5.7,16.3)^{*}$ & $9.0(4.1,19.9)^{*}$ & $0.7(0.3,1.5)$ \\
DR Congo & $6.0(4.5,8.0)^{*}$ & $2.7(2,3.8)^{*}$ & $1.6(0.8,3.4)$ \\
Ethiopia & $9.5(6.1,14.9)^{*}$ & $5.9(3.1,11.4)^{*}$ & $1.5(0.2,9.9)$ \\
Mali & $10.3(4.7,22.6)^{*}$ & $6.5(3.9,10.9)^{*}$ & $1.6(0.9,2.8)$ \\
Niger & $5.2(2.5,11.0)^{*}$ & $13.0(9.4,18.2)^{*}$ & $1.4(0.8,2.5)$ \\
Nigeria & $4.4(3.2,6.2)^{*}$ & $3.8(2.2,6.5)^{*}$ & $0.8(0.4,1.6)^{*}$ \\
Sierra Leone & $0.9(0.7,1.4)$ & $1.4(0.9,2.3)$ & $0.9(0.3,3.1)$ \\
Tanzania & $7.1(3.7,13.6)^{*}$ & $5.1(3.2,8.1)^{*}$ & $1.8(0.7,4.7)$ \\
Uganda & $3.3(2.2,4.9)^{*}$ & $6.5(4.2,10.1)^{*}$ &
\end{tabular}

*Significantly different from 1 with $\mathrm{p}<0.05$

*The final model measuring the probability of 'good' diarrhea management on source of care was adjusted by the following variables

- predisposing characteristics -child's age, mother's age, child's gender, mother's marital status and education, number of children under five living in household

- enabling resources- wealth quintile, rural or urban location, if distance is a problem in receiving health care, participating in decision making, household improved water access

- need characteristic -whether there was blood in the child's stool 
taken to health facility for care had good diarrhea management more often than those with no care (Table 10 in the Appendix).

The adjusted effects of community care versus facility care on the probability of receiving good diarrhea management are shown in Fig. 3. Careseeking from health facilities does not appear to result systematically in higher likelihood of good diarrhea management than care from community providers. In two countries (Niger and Uganda), community care was of higher quality than facility care, and in four countries (Burkina Faso, Burundi, Cameroon and DR Congo) management for those with community care is lower than facility care. In the remaining six, there is no statistically significant difference in the quality of diarrhea management between these two sources of care.

\section{Discussion}

Diarrhea remains a high burden disease despite the availability of simple, affordable, and effective treatments. Recent studies have shown high levels of harmful practices during childhood diarrhea, including the curtailment of fluids and food during illness episodes [3, 13, 16, 17, 23]. This analysis assesses the quality of diarrhea management by source of care in twelve sub-Saharan African countries in which diarrhea is a major cause of under-five deaths. Based on mothers' reports of the treatment given to their children during episodes of diarrhea in the 2 weeks preceding the survey, we categorized diarrhea management practice as good, fair or poor based on WHO/UNICEF recommendations. We then assessed the association between 'good' diarrhea management practice and the source of care, distinguishing between care from health facilities, community care, traditional care and no care outside the home. The results indicate that few children are given high quality care for diarrhea in 11 of the 12 countries (range $17 \%$ to $38 \%$ with a median of $27 \%$ ). Particularly striking is the pervasiveness and high levels of poor diarrhea management, ranging from $38 \%$ to $63 \%$ with a median of $49 \%$. Of the 12 countries, Sierra Leone is the exception with the highest level of good management: about two-thirds of children $(67 \%)$ with diarrhea provided with good management and only about $10 \%$ of children provided with 'poor' management.

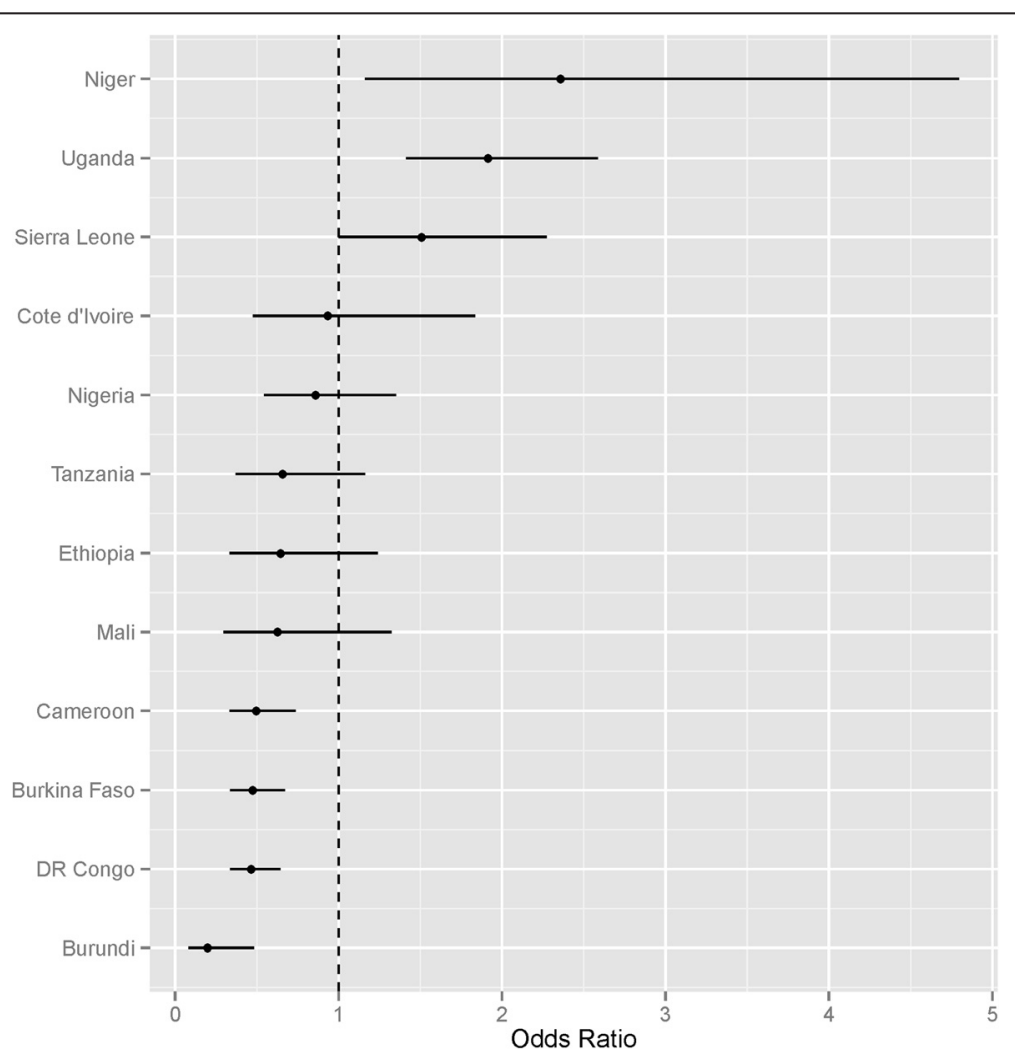

Fig. 3 Adjusted odds ratio of good diarrhea management, for those who were taken to community-based care, compared to those who were taken to health facilities for care. Note to Fig. 3 text: If odds ratios and confidence intervals are higher than 1, the average management for those who sought community care was superior to those who sought facility care. If odds ratios and confidence intervals are lower than 1 , the average management for those who sought community care was inferior to those who sought facility care 
Low levels of coverage of ORS is a major driver of poor diarrhea quality care. Except in Sierra Leone, where ORS coverage in 2013 was $85 \%$-and has been consistently over $50 \%$ since at least 2005-, coverage of ORS was below $50 \%$ in all countries, and was only $17 \%$ in Cote d'Ivoire and Cameroon.

Why is the quality of diarrhea management so much better in Sierra Leone than in the other 11 countries studied? We explored possible reasons, keeping in mind that challenges to the health systems associated with the recent Ebola epidemic have had a negative impact on child health care since 2013 [18]. Sierra Leone's success in scaling up basic child health interventions, including ORS, has been attributed to several important contextual factors $[24,6,25]$, including the opportunity to rebuild the health system after the 11-year civil war that ravaged the country between 1999 and 2002 and displaced as many as 2 million out of the 5.5 million population. The war also took a particular toll of the country's health infrastructure [23, 24]. During these years, a large proportion of the population lived in internally displaced population camps. In camps, cholera outbreaks were not uncommon and were mostly managed with ORS largely distributed by community volunteers referred to as "Blue Flag Volunteers". ORS was widely accessible and available in attractive orange-flavor low-osmolarity formulation. Following the civil war, nationwide efforts were made to ensure that the supply chain was maintained at each level [23]. Deployment of community health volunteers was also associated with a reduced treatment burden at facilities and less reliance on traditional treatments [25]. As part of this transformation, in April 2010 the government of Sierra Leone abolished healthcare costs for pregnant women, new mothers and children under five. As a result, many more pregnant women, new mothers and their young children are now coming to health centers [10]. The particular case of Sierra Leone shows that through strong government support and local efforts, important health intervention can be scaled up in a sustained manner.

Across countries, our analysis further showed that children with diarrhea for whom care was sought from health facilities or community health providers were more likely to receive good management than those for whom care was sought from traditional or informal sources or those for whom no care was sought. Thus, although treatment of diarrhea is simple and can be managed at home with appropriate knowledge and supplies, it is essential to continue to recommend that children with diarrhea seek appropriate care from facilities or health community services. This recommendation must be accompanied by significant improvement in quality of care at health facilities and community health providers. Poor quality of care at health facilities and community health workers represents an enormous missed opportunity to prevent unnecessary child deaths due to diarrhea.

The comparisons by type of provider revealed that in six of the countries, children for whom care was sought from community-based health providers are equally likely to have been given 'good' management as those for whom care was sought from health facilities. This, further corroborates studies of quality of care provided by community health workers that demonstrated that this health cadre can provide treatment services of the same quality as health facilities $[11,14]$.

There are limitations in our analysis that should be considered when interpreting the findings. Our measure of diarrhea management practice was based mother's recall of care provided to the child during episode of diarrhea. This could have led to differential recall bias and may not entirely reflect the level of quality of care in facilities or from community-based workers. For instance, mothers are more likely to recall ORS than, other treatments like zinc, which might be misremembered as an antibiotic or other medication. The growing body of research on the validity of mothers' reports of child survival interventions has also raised important issues that are likely to apply here [2] and could only be addressed through carefully designed validation studies. We were also unable to assess the severity of the diarrhea, which may affect mother's decisions about careseeking as well as the type of management received at the health facility. Further studies are needed to explore the role of local and cultural beliefs and practices in determining caregiver understandings of diarrhea and appropriate responses are also important, and will require further study using qualitative methodologies [4].

\section{Conclusions}

Despite these limitations, the findings presented in this paper show clearly that there is an important missed opportunity to prevent child deaths due to diarrhea by making sure that health care providers are managing childhood diarrhea appropriately, including advising caregivers effectively about providing 'good' diarrhea management at home and the importance of seeking care outside the home. Although there is variation across countries, the results also suggest that community-based providers can provide access to management at levels of quality comparable to that provided at health facilities, lending support to advocates of more widespread implementation of iCCM strategies. 


\section{Appendix}

Table 4 Estimates on diarrhea specific mortality among children under five and evolution of the adoption and implementation of the national policy on low-osmolarity ORS and zinc for management of diarrhea - Sub-Saharan African countries

\begin{tabular}{|c|c|c|c|c|c|}
\hline \multirow[b]{2}{*}{ Country } & \multicolumn{2}{|l|}{2015 estimates } & \multicolumn{3}{|c|}{$\begin{array}{l}\text { Status of policy on low osmolarity ORS } \\
\text { and zinc for management of diarrhea }\end{array}$} \\
\hline & $\begin{array}{l}\text { Total } n \text {. under five deaths } \\
\text { due to diarrhea }\end{array}$ & $\begin{array}{l}\% \text { deaths among children 1-59 months } \\
\text { caused by diarrhea }\end{array}$ & 2008 & 2010 & 2015 \\
\hline Angola & 24,927 & $21 \%$ & No & Partial & Yes \\
\hline Benin & 3,996 & $16 \%$ & Yes & Yes & Yes \\
\hline Botswana & 157 & $13 \%$ & Partial & Yes & Yes \\
\hline Burkina Faso ${ }^{a}$ & 4,975 & $12 \%$ & Yes & Yes & Yes \\
\hline Burundi ${ }^{\mathrm{a}}$ & 3,716 & $15 \%$ & Partial & Partial & Yes \\
\hline Cabo Verde & 14 & $10 \%$ & - & - & - \\
\hline Cameroon & 8,032 & $16 \%$ & Yes & Yes & Yes \\
\hline Central African Republic & 2,194 & $15 \%$ & - & No & No \\
\hline Chad & 11,360 & $19 \%$ & Yes & Yes & Yes \\
\hline Comoros & 142 & $13 \%$ & - & - & Yes \\
\hline Congo & 519 & $12 \%$ & Yes & Yes & Yes \\
\hline Côte d'Ivoire ${ }^{a}$ & 5,697 & $13 \%$ & Partial & Partial & Yes \\
\hline Democratic Republic of the Congo ${ }^{a}$ & 32,047 & $15 \%$ & Yes & Yes & Yes \\
\hline Djibouti & 116 & $16 \%$ & - & Yes & Yes \\
\hline Equatorial Guinea & 200 & $11 \%$ & Yes & Yes & Yes \\
\hline Eritrea & 694 & $14 \%$ & Partial & Partial & Yes \\
\hline Ethiopia $^{a}$ & 15,535 & $15 \%$ & Yes & Yes & Yes \\
\hline Gabon & 160 & $11 \%$ & Yes & Yes & Yes \\
\hline Gambia & 487 & $16 \%$ & - & No & Yes \\
\hline Ghana & 3,657 & $12 \%$ & Partial & Yes & Yes \\
\hline Guinea & 3,506 & $12 \%$ & Yes & No & Yes \\
\hline Guinea-Bissau & 562 & $17 \%$ & No & Partial & Yes \\
\hline Kenya & 5,442 & $13 \%$ & Yes & Yes & Yes \\
\hline Lesotho & 541 & $15 \%$ & Yes & Partial & Yes \\
\hline Liberia & 937 & $13 \%$ & Partial & Yes & Yes \\
\hline Madagascar & 3,665 & $15 \%$ & Yes & Yes & Yes \\
\hline Malawi & 3,062 & $11 \%$ & Partial & Yes & Yes \\
\hline Malia & 7,807 & $14 \%$ & Partial & Partial & Yes \\
\hline Mauritania & 1,186 & $18 \%$ & No & No & - \\
\hline Mauritius & 5 & $6 \%$ & - & - & - \\
\hline Mozambique & 7,341 & $13 \%$ & Partial & Partial & Yes \\
\hline Namibia & 299 & $14 \%$ & - & - & - \\
\hline Niger $^{a}$ & 9,873 & $16 \%$ & Yes & Yes & Yes \\
\hline Nigeria $^{a}$ & 76,980 & $15 \%$ & Yes & Yes & Yes \\
\hline Rwanda & 1,033 & $13 \%$ & Yes & Yes & Yes \\
\hline Sao Tome and Principe & 23 & $12 \%$ & - & - & Yes \\
\hline Senegal & 2,403 & $16 \%$ & Yes & Yes & Yes \\
\hline Seychelles & 0 & $2 \%$ & - & - & - \\
\hline
\end{tabular}


Table 4 Estimates on diarrhea specific mortality among children under five and evolution of the adoption and implementation of the national policy on low-osmolarity ORS and zinc for management of diarrhea - Sub-Saharan African countries (Continued)

\begin{tabular}{|c|c|c|c|c|c|}
\hline Sierra Leone ${ }^{a}$ & 2,784 & $15 \%$ & Partial & Yes & Yes \\
\hline Somalia & 8,759 & $20 \%$ & - & Partial & Yes \\
\hline South Africa & 3,627 & $12 \%$ & Yes & Yes & Yes \\
\hline South Sudan & 3,243 & $14 \%$ & - & - & No \\
\hline Sudan & 9,536 & $18 \%$ & Yes & Yes & Yes \\
\hline Swaziland & 230 & $13 \%$ & - & Yes & Yes \\
\hline Togo & 1,636 & $13 \%$ & Yes & Yes & Yes \\
\hline Uganda $^{a}$ & 7,001 & $12 \%$ & Yes & Yes & Yes \\
\hline United Republic of Tanzania ${ }^{a}$ & 8,000 & $13 \%$ & Yes & Yes & Yes \\
\hline Zambia & 3,469 & $13 \%$ & Yes & Yes & Yes \\
\hline Zimbabwe & 3,677 & $14 \%$ & Yes & Yes & Yes \\
\hline
\end{tabular}

Notes:

Indicator: Low-osmolarity oral rehydration salts and zinc for management of diarrhea

Definition: National policy on management of diarrhoea with low-osmolarity oral rehydration salts and zinc has been adopted and implemented

Criteria for ranking

Yes: national policy or guidelines adopted on use of low-osmolarity oral rehydration salts and zinc for management of diarrhoea

No: no national policy or guidelines adopted on the use of low-osmolarity oral rehydration salts and zinc for managements of diarrhoea

Partial: National policy or guidelines adopted on use of low osmolarity ORS and zinc for management of diarrhoea but no implementation; OR no national policy

or guidelines adopted but implementation in selected areas; OR national policy or guidelines adopted and/or implementation commenced for either low

osmolarity ORS or zinc use, but not for both

Source: Mortality estimates from WHO-MCEE estimates of child cause of death, 2000-2015 and policy data from WHO Global Maternal Newborn Child and Adoles-

cent Health Policy Indicator Survey by the World Health Organization Department of Maternal Child Adolescent Health

${ }^{a}$ Countries included in the analysis 
Table 5 Classification of sources of care for child diarrhea in countries included in the analysis (categories are those included in the DHS data used in the analysis)

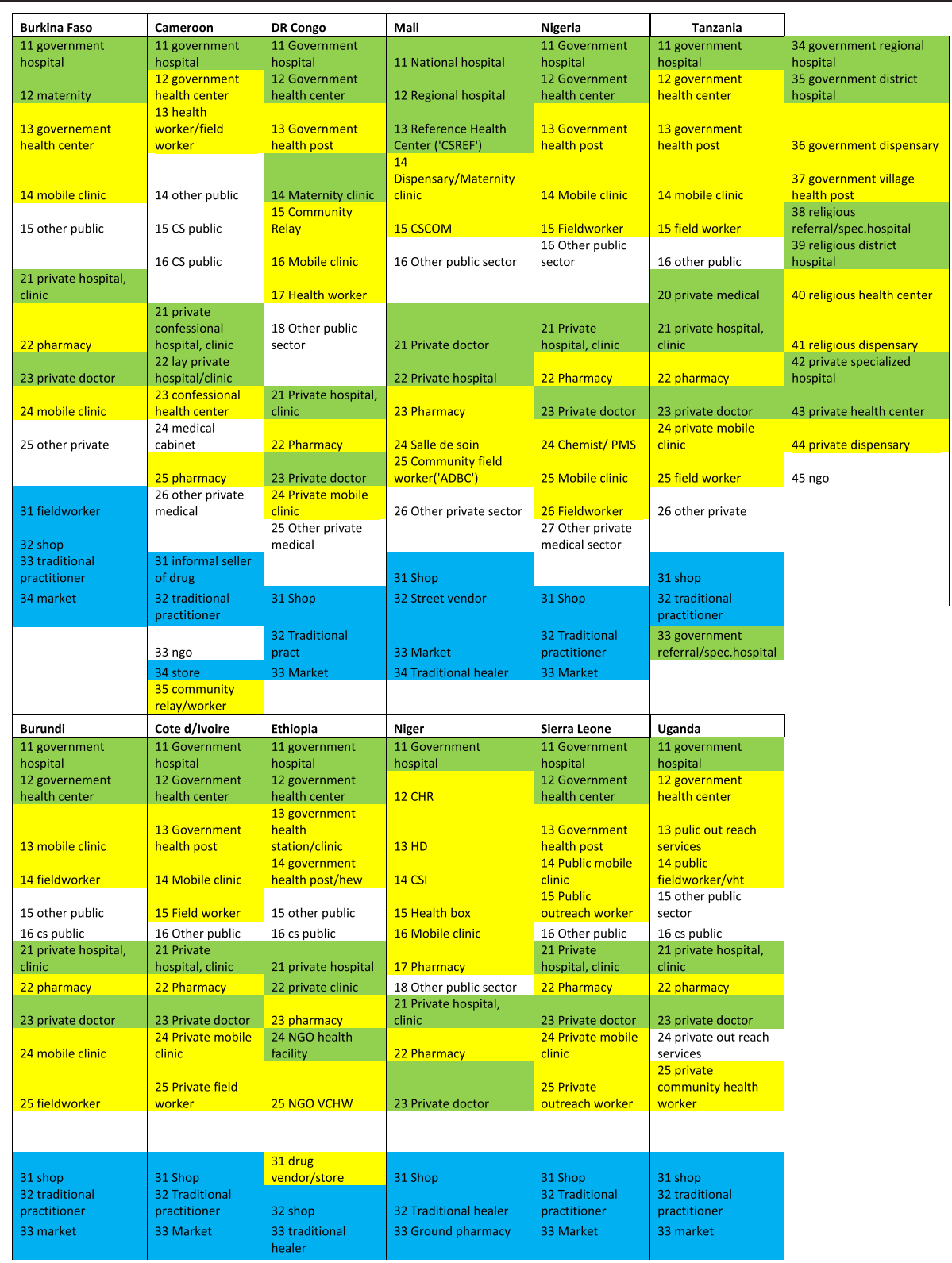

Classification of country specific sources of care was done exclusively for this analysis and as determined by country and by the specific health systems in place. Ministries of Health in each countries were consulted for this classification

Facility

Community

Traditional/ informal 
Table 6 Adjusted coefficients (log odds ratios) from logistic regression models of good diarrhea management adjusting for factors from Anderson's conceptual framework. Associations that are significantly different from zero at $p=0.05$ are shown in red

\begin{tabular}{|c|c|c|c|c|c|c|c|c|c|c|c|c|}
\hline \multirow[b]{2}{*}{ Country } & \multicolumn{12}{|c|}{ Factor } \\
\hline & $\begin{array}{l}\text { Child's } \\
\text { Age } \\
\text { (months) }\end{array}$ & $\begin{array}{l}\text { Mother's } \\
\text { Age } \\
\text { (years) }\end{array}$ & $\begin{array}{l}\text { Sex } \\
\text { (referenc } \\
\text { e } \\
\text { category } \\
\text { =female) }\end{array}$ & $\begin{array}{l}\text { Mother } \\
\text { is } \\
\text { married } \\
\text { or in } \\
\text { union }\end{array}$ & $\begin{array}{l}\text { Mother's } \\
\text { Education }\end{array}$ & $\begin{array}{l}\text { Number of } \\
\text { children in } \mathrm{HH}\end{array}$ & $\begin{array}{l}\text { Wealth } \\
\text { Index }\end{array}$ & $\begin{array}{l}\text { Area } \\
\text { (referen } \\
\text { ce } \\
\text { category } \\
\text { =rural) } \\
\end{array}$ & $\begin{array}{l}\text { Distance } \\
\text { is } \\
\text { problem }\end{array}$ & $\begin{array}{l}\text { Respond } \\
\text { ent } \\
\text { decides } \\
\text { on own } \\
\text { health } \\
\text { car } \\
\end{array}$ & $\begin{array}{l}\text { Improv } \\
\text { ed } \\
\text { water } \\
\text { source }\end{array}$ & $\begin{array}{l}\text { Blood } \\
\text { in } \\
\text { stool } \\
\end{array}$ \\
\hline Burkina Faso & 0.00 & 0.00 & 0.10 & 0.27 & 0.02 & -0.12 & 0.12 & -0.12 & 0.16 & 0.00 & 0.27 & 0.15 \\
\hline Burundi & 0.00 & 0.00 & 0.14 & 0.36 & 0.07 & -0.12 & 0.05 & 0.08 & -0.06 & 0.05 & -0.04 & -0.23 \\
\hline Cameroon & -0.03 & 0.00 & 0.13 & 0.03 & 0.06 & -0.04 & 0.12 & -0.26 & -0.05 & -0.22 & 0.07 & 0.41 \\
\hline Cote d'Ivoire & -0.01 & 0.02 & -0.28 & 0.12 & 0.18 & -0.04 & 0.31 & 0.63 & 0.04 & -0.18 & -0.40 & 0.09 \\
\hline DR Congo & 0.00 & 0.01 & -0.06 & 0.19 & 0.02 & 0.09 & 0.09 & -0.41 & 0.04 & 0.13 & -0.28 & -0.04 \\
\hline Ethiopia & 0.02 & 0.01 & -0.17 & -0.07 & 0.43 & -0.08 & -0.11 & 0.58 & -0.26 & 0.01 & 0.52 & 0.23 \\
\hline Mali & 0.01 & 0.03 & -0.13 & -0.80 & -0.11 & 0.04 & 0.20 & 0.26 & 0.41 & 0.27 & -0.19 & -0.02 \\
\hline Niger & 0.01 & 0.01 & 0.03 & 0.89 & -0.11 & 0.03 & 0.11 & -0.37 & 0.08 & -0.16 & 0.04 & -0.08 \\
\hline Nigeria & 0.00 & -0.01 & 0.02 & -0.18 & -0.03 & 0.04 & 0.27 & -0.19 & -0.48 & 0.17 & 0.12 & -0.09 \\
\hline Sierra Leone & 0.01 & -0.01 & -0.01 & -0.09 & -0.03 & -0.05 & -0.01 & -0.08 & -0.22 & 0.29 & -0.12 & -0.59 \\
\hline Tanzania & 0.02 & 0.00 & 0.04 & 0.16 & 0.04 & -0.05 & 0.02 & 0.10 & -0.47 & 0.01 & -0.33 & 0.16 \\
\hline Uganda & 0.01 & -0.02 & 0.13 & -0.16 & 0.06 & 0.07 & 0.06 & 0.01 & -0.15 & 0.08 & -0.13 & 0.02 \\
\hline
\end{tabular}

Table 7 Number of household and women surveyed and response rates by country

\begin{tabular}{lllll}
\hline Country & Survey Year & Household $(\mathrm{N})$ & Women 15-49 years old $(\mathrm{N})$ & Response rate for women (\%) \\
\hline Burkina Faso & 2010 & 8,619 & 10,364 & 98.4 \\
Burundi & 2010 & 4,807 & 4,916 & 95.5 \\
Cameroon & 2011 & 6,537 & 7,655 & 96.4 \\
Cote d'Ivoire & 2011 & 4,553 & 5,431 & 91.0 \\
DR Congo & 2013 & 10,428 & 11,293 & 98.5 \\
Ethiopia & 2011 & 7,534 & 7,764 & 93.2 \\
Mali & 2012 & 5,982 & 6,723 & 94.4 \\
Niger & 2012 & 6,673 & 7,680 & 93.5 \\
Nigeria & 2013 & 17,723 & 20,192 & 96.7 \\
Sierra Leone & 2013 & 7,263 & 8,524 & 96.5 \\
Tanzania & 2010 & 4,907 & 5,358 & 95.2 \\
Uganda & 2011 & 4,618 & 4,909 & 89.4 \\
\hline
\end{tabular}


Table 8 Percent of children under five with diarrhea in the 2 weeks prior to the survey by type of diarrhea management practice (good, fair or poor) and provider

\begin{tabular}{|c|c|c|c|c|c|c|c|c|c|c|c|c|}
\hline & \multicolumn{12}{|c|}{ Careseeking for Diarrhea $^{a}$} \\
\hline & \multicolumn{3}{|c|}{ Facility Care } & \multicolumn{3}{|c|}{ Community Care } & \multicolumn{3}{|c|}{ Traditional Care } & \multicolumn{3}{|c|}{ No Care outside the home } \\
\hline & $\begin{array}{l}\text { Good } \\
\text { Practice }\end{array}$ & $\begin{array}{l}\text { Fair } \\
\text { Practice }\end{array}$ & $\begin{array}{l}\text { Poor } \\
\text { Practice }\end{array}$ & $\begin{array}{l}\text { Good } \\
\text { Practice }\end{array}$ & $\begin{array}{l}\text { Fair } \\
\text { Practice }\end{array}$ & $\begin{array}{l}\text { Poor } \\
\text { Practice }\end{array}$ & $\begin{array}{l}\text { Good } \\
\text { Practice }\end{array}$ & $\begin{array}{l}\text { Fair } \\
\text { Practice }\end{array}$ & $\begin{array}{l}\text { Poor } \\
\text { Practice }\end{array}$ & $\begin{array}{l}\text { Good } \\
\text { Practice }\end{array}$ & $\begin{array}{l}\text { Fair } \\
\text { Practice }\end{array}$ & $\begin{array}{l}\text { Poor } \\
\text { Practice }\end{array}$ \\
\hline $\begin{array}{l}\text { Burkina } \\
\text { Faso }\end{array}$ & $47 \%$ & $24 \%$ & $29 \%$ & $28 \%$ & $19 \%$ & $53 \%$ & $5 \%$ & $24 \%$ & $72 \%$ & $6 \%$ & $20 \%$ & $74 \%$ \\
\hline Burundi & $51 \%$ & $23 \%$ & $26 \%$ & $17 \%$ & $40 \%$ & $43 \%$ & $17 \%$ & $13 \%$ & $70 \%$ & $9 \%$ & $28 \%$ & $63 \%$ \\
\hline Cameroon & $59 \%$ & $27 \%$ & $14 \%$ & $40 \%$ & $39 \%$ & $21 \%$ & $8 \%$ & $45 \%$ & $47 \%$ & $8 \%$ & $47 \%$ & $46 \%$ \\
\hline $\begin{array}{l}\text { Cote } \\
\text { d'Ivoire }\end{array}$ & $42 \%$ & $26 \%$ & $32 \%$ & $40 \%$ & $24 \%$ & $36 \%$ & $5 \%$ & $28 \%$ & $67 \%$ & $8 \%$ & $34 \%$ & $58 \%$ \\
\hline DR Congo & $56 \%$ & $21 \%$ & $22 \%$ & $37 \%$ & $24 \%$ & $38 \%$ & $24 \%$ & $21 \%$ & $55 \%$ & $19 \%$ & $22 \%$ & $59 \%$ \\
\hline Ethiopia & $42 \%$ & $31 \%$ & $27 \%$ & $33 \%$ & $25 \%$ & $42 \%$ & $10 \%$ & $21 \%$ & $69 \%$ & $7 \%$ & $12 \%$ & $81 \%$ \\
\hline Mali & $61 \%$ & $21 \%$ & $18 \%$ & $50 \%$ & $24 \%$ & $26 \%$ & $21 \%$ & $18 \%$ & $61 \%$ & $15 \%$ & $19 \%$ & $66 \%$ \\
\hline Niger & $52 \%$ & $19 \%$ & $29 \%$ & $63 \%$ & $22 \%$ & $16 \%$ & $16 \%$ & $17 \%$ & $67 \%$ & $12 \%$ & $18 \%$ & $70 \%$ \\
\hline Nigeria & $37 \%$ & $19 \%$ & $44 \%$ & $32 \%$ & $23 \%$ & $45 \%$ & $6 \%$ & $10 \%$ & $83 \%$ & $12 \%$ & $10 \%$ & $79 \%$ \\
\hline $\begin{array}{l}\text { Sierra } \\
\text { Leone }\end{array}$ & $64 \%$ & $28 \%$ & $8 \%$ & $72 \%$ & $23 \%$ & $6 \%$ & $67 \%$ & $17 \%$ & $16 \%$ & $68 \%$ & $17 \%$ & $16 \%$ \\
\hline Tanzania & $56 \%$ & $10 \%$ & $33 \%$ & $49 \%$ & $16 \%$ & $35 \%$ & - & - & - & $16 \%$ & $9 \%$ & $75 \%$ \\
\hline Uganda & $34 \%$ & $21 \%$ & $45 \%$ & $49 \%$ & $25 \%$ & $26 \%$ & $19 \%$ & $18 \%$ & $63 \%$ & $13 \%$ & $14 \%$ & $73 \%$ \\
\hline
\end{tabular}

${ }^{\mathrm{a}} \mathrm{A}$ test for difference in diarrhea management practice for different provider type is highly significant in each of these twelve surveys. This was an overall test of association, indicating that the average diarrhea management is different by source of care

Table 9 Unadjusted odds ratios and $95 \%$ confidence intervals for 'good' diarrhea management

\begin{tabular}{|c|c|c|c|}
\hline \multicolumn{4}{|c|}{ Unadjusted odds ratio and $95 \%$ confidence interval for good management (Reference: no care outside the home) } \\
\hline & Facility Care & Community Care & Traditional Care \\
\hline Burkina Faso & $13.8(9.2,20.8)^{*}$ & $6(4.2,8.4)^{*}$ & $0.7(0.3,1.8)$ \\
\hline Burundi & $10.9(8.2,14.5)^{*}$ & $2.2(0.9,5.7)$ & $2.2(0.7,6.7)$ \\
\hline Cameroon & $17.4(11.7,25.9)^{*}$ & $7.9(5.4,11.6)^{*}$ & $1.0(0.6,1.6)$ \\
\hline Cote d'Ivoire & $8.4(5,14.3)^{*}$ & $7.7(3.6,16.4)^{*}$ & $0.6(0.3,1.4)$ \\
\hline DR Congo & $5.4(4.1,7.1)^{*}$ & $2.6(1.9,3.5)^{*}$ & $1.4(0.7,2.9)$ \\
\hline Ethiopia & $9.3(6,14.2)^{*}$ & $6.3(3.2,12.3)^{*}$ & $1.4(0.2,12.2)$ \\
\hline Mali & $9.2(4.5,18.9)^{*}$ & $5.8(3.5,9.6)^{*}$ & $1.6(0.9,2.8)$ \\
\hline Niger & $8(3.5,17.9)^{*}$ & $12.1(8.8,16.6)^{*}$ & $1.4(0.8,2.4)$ \\
\hline Nigeria & $4.4(3.1,6.1)^{*}$ & $3.5(2.0,5.9)^{*}$ & $0.5(0.3,1.0)^{*}$ \\
\hline Sierra Leone & $0.9(0.6,1.3)$ & $1.3(0.8,2.1)$ & $1.0(0.3,3.4)$ \\
\hline Tanzania & $7.1(3.8,13.4)^{*}$ & $5.2(3.3,8.4)^{*}$ & \\
\hline Uganda & $3.6(2.4,5.2)^{*}$ & $6.6(4.4,10.1)^{*}$ & $1.7(0.6,4.4)$ \\
\hline
\end{tabular}

*Significantly different from 1 with $p<0.05$ 
Table 10 Crude odds ratios and $95 \%$ confidence intervals for good diarrhea management among children age 0 to 5 months

\begin{tabular}{|c|c|c|c|}
\hline & \multicolumn{3}{|c|}{$\begin{array}{l}\text { Crude odds ratio and } 95 \% \text { confidence interval for good management among children age 0-5 months (Reference: no care outside } \\
\text { the home) }\end{array}$} \\
\hline & Facility Care & Community Care & Traditional Care \\
\hline Burkina Faso & $2.1(0.6,7.4)$ & $0.8(0.3,2.6)$ & $0.3(0.1,1.6)$ \\
\hline Burundi & $1.2(0.5,2.9)$ & $N E$ & $N E$ \\
\hline Cameroon & $5.8(1.1,31.8)^{*}$ & $2.2(0.7,6.8)$ & $0.9(0.2,3.7)$ \\
\hline Cote d'Ivoire & $1.1(0.3,4.3)$ & $0.6(0.1,4)$ & $0.4(0.1,2.7)$ \\
\hline DR Congo & $2.9(1.1,7.5)^{*}$ & $1.5(0.7,3.3)$ & $5(1.3,19.3)^{*}$ \\
\hline Ethiopia & $8.4(1.9,37.7)^{*}$ & $6.7(0.9,47.9)$ & $N E$ \\
\hline Mali & $1.1(0.1,12.1)$ & $9.7(2.4,38.4)^{*}$ & $0.9(0.2,4.2)$ \\
\hline Niger & $N E$ & $4.3(2,9.1)^{*}$ & $1.7(0.5,6.6)$ \\
\hline Nigeria & $8.1(2.2,29.4)^{*}$ & $12.7(2.5,63.7)^{*}$ & $1.2(0.1,11.1)$ \\
\hline Sierra Leone & $3.4(1.1,10.7)^{*}$ & $51.4(4.6,571.3)^{*}$ & $N E$ \\
\hline Tanzania & $0.5(0,6.1)$ & $3.1(0.9,11.3)$ & $N E$ \\
\hline Uganda & $1.2(0.4,3.5)$ & $1.8(0.7,5)$ & NE \\
\hline
\end{tabular}

$\mathrm{NE}$, not estimable

*Significantly different from 1 with $p<0.05$

\section{Acknowledgements}

We would like to thank Robert Bain at UNICEF, who provided advice on measurement of water, sanitation and hygiene indicators.

\section{Funding}

This work was funded through a sub-grant from the U.S. Fund for UNICEF under the [5] for Maternal, Newborn and Child Survival grant from the Bill \& Melinda Gates Foundation, Grant \#OPP1058954.

\section{Availability of data and materials}

This research uses national survey data that is publicly available for research collected by and DHS (http:/www.dhsprogram.com).

\section{Authors' contribution}

$L C V$ wrote the first draft of the paper with inputs from AAm, JB, JP, HN. JP analyzed survey data and wrote the first draft of the methods and results. $H N, J B$, and LCV provided interpretation and refinement for issues relating to analysis. JB wrote the initial discussion and conclusions. JB, AAm and HN provided overall guidance and helped refined the research question. All authors contributed to editing the final manuscript. All authors read and approved the final manuscript.

\section{Competing interests}

The authors declare that they have no competing interests.

\section{Consent for publication}

Not applicable.

\section{Ethics approval and consent to participate}

The survey data analyzed in this research was collected and managed by local government entities with technical support from MICS and DHS. In each country, these government entities managed and approved the informed consent process and other ethical issues. Prior to public release MICS and DHS make their data anonymous. All data used in this research are anonymous and not identifiable, and so there was no need to seek further ethical approval for data use. All the data used for the study were publicly available.

\section{Author details}

'United Nations Children's Fund UNICEF, 3 UN Plaza, New York City, NY 10017, USA. ${ }^{2}$ Johns Hopkins University, International Health, Baltimore, USA. ${ }^{3}$ Université catholique de Louvain, Louvain-la-Neuve, Belgium. ${ }^{4}$ Obafemi
Awolowo University, lle Ife, Nigeria. ${ }^{5}$ Addis Ababa University, School of Public Health, Addis Ababa, Ethiopia.

Received: 15 October 2015 Accepted: 10 August 2016 Published online: 19 August 2016

\section{References}

1. Andersen RM. Revisiting the Behavioral Model and Access to Medical Care: Does it Matter. J Health Soc Behav. 1995;36(1):1-10.

2. Bryce J, Arnold F, Blanc A, Hancioglu A, Newby H, Requejo J, et al. Measuring Coverage in MNCH: New Findings, New Strategies, and Recommendations for Action. PLoS Med. 2013;10(5):e1001423. doi:10.1371/ journal.pmed.1001423.

3. Carter E, Bryce J, Perin J, Newby H. Harmful practices in the management of childhood diarrhea in low- and middle-income countries: a systematic review. BioMed Central. 2014, In Press.

4. Colvin C, et al. Understanding care seeking for child illness in sub-Saharan Africa: A systematic review and conceptual framework based on qualitative research of household recognition and response to child diarrhea, pneumonia and malaria. Soc Sci Med. 2013:86:66-78.

5. Countdown to, 2015. 'Countdown to 2015 for Maternal, Newborn and Child Survival. 2015. Available at http://www.countdown2015mnch.org/', Accessed 15 May.

6. Diaz, T., George AS, Rao SR, Bangura PS, Baimba JB, McMahon SA, Kabano A. 'Healthcare seeking for diarrhoea, malaria and pneumonia among children in four poor rural districts in Sierra Leone in the context of free health care: results of a cross-sectional survey'. BMC Public Health 2013;13:157.

7. Demographic and Health Surveys, DHS (2010-2014) for Burkina Faso 2010 Burundi 2010, Cameroon 2011, Cote d'Ivoire 2011-12, Democratic Republic of the Congo 2013-14, Ethiopia 2011, Mali 2012-13, Niger 2012, Nigeria 2013, Sierra Leone 2013, United Republic of Tanzania 2010, and Uganda 2011, ICF International, Calverton Maryland USA

8. Fischer Walker CL, Taneja S, LeFevre A, Black RE, Mazumder S. Appropriate Management of Acute Diarrhea in Children Among Public and Private Providers in Gujarat, India: A Cross-Sectional Survey. Glob Health Sci Pract. 2015;3(2):230-41.

9. Fischer Walker, CL Rudan I, Liu L, Nair H, Theodoratou E, Bhutta Z, O'Brien $\mathrm{KL}$, Campbell H, Black RE. 'Global burden of childhood pneumonia and diarrhea'. Lancet. 2013;381(9875):1405-16.

10. Health Poverty Action HPA. Sierra Leone's free Healthcare initiative. 2012. http://www.healthpovertyaction.org/wp-content/uploads/downloads/2012/ 07/SierraLeoneFHIbriefingweb12.pdf 
11. Gilroy KE, Callaghan-Koru JA, Cardemil CV, et al., on behalf of the CCM-Malawi Quality of Care Working Group. (2012). Quality of sick child care delivered by Health Surveillance Assistants in Malawi. Health Policy Plan. 2013;28(6):573-85.

12. Liu L, et al. Global, regional, and national causes of child mortality in 200013, with projections to inform post-2015 priorities: an updated systematic analysis. Lancet. 2015;385:430-40.

13. Mediratta RP, Feleke A, Moulton LH, Yifru S, Sack RB. Risk factors and case management of acute diarrhoea in North Gondar Zone, Ethiopia. J Health Popul Nutr. 2010;28(3):253-63.

14. Miller NP, Amouzou A, Tafesse M, et al. Integrated community case management of childhood illness in Ethiopia: Implementation strength and quality of care. Am J Trop Med Hyg. 2014;91(2):424-34.

15. Munos Melinda K, Fischer W, Christa L, Black Robert E. 'The effect of oral rehydration solution and recommended home fluids on diarrhoea mortality'. Int J Epidemiol. 2010;39:i-75-87.

16. Perin J, Carvajal-Velez L, Carter E, Bryce J, Newby H. Fluid curtailment during childhood diarrhea: A Countdown analysis. BMC Public Health. 2015;15:588. http://www.biomedcentral.com/content/pdf/s12889-015-1878-z.pdf Accessed 26 June 2015.

17. Saha D, Akinsola A, Sharples K, Adeyemi MO, Antonio M, Imran S, Jasseh M, Hossain MJ, Nasrin D, Kotloff KL, et al. Health Care Utilization and Attitudes Survey: understanding diarrheal disease in rural Gambia. Am J Trop Med Hyg. 2013;89(1 Suppl):13-20

18. UNICEF. Sierra Leone Health Facility Survey 2014 - Assessing the impact of the EVD outbreak on health systems in Sierra Leone - Survey conducted 617 October 2014. 2014

19. UNICEF. 'Global databases based on Multiple Indicators Cluster Surveys, Demographic and Health Surveys and other nationally representative sources.'2015a. Accessed May 2015. (New York.).

20. UNICEF. 'Multiple Indicator Cluster Surveys website. 2015b. www.data.unicef. org', Accessed 10 June 2015.

21. WHO-CHERG. 'Estimates for child causes of death 2000-2013. 2014. http:// www.who.int/healthinfo/global_burden_disease/estimates_child_cod_2013/ en/.

22. WHO/UNICEF. Joint stament: clinical managent of acute diarrhea. Geneva: WHO; 2004

23. Wilson SE, Morris SS, Gilbert SS. Sierra Leone ORS case study. Seattle, 2012. Available from: http://www.shopsproject.org/sites/default/files/resources/ Sierra\%20Leone_ORS\%20Case\%20Study.pdf. Accessed 30 July 2015.

24. Wilson SE, Morris SS, Gilbert SS, Mosites E, Hackleman R, Weum KLM, et al. Scaling up access to oral rehydration solution for diarrhea: Learning from historical experience in low- and high-performing countries. J Glob Health. 2013;3(No. 1):010404. doi:10.7189/jogh.03.010404.

25. Yansaneh Al, Moulton LH, George AS, Rao SR, Kennedy N, Bangura P, Brieger WR, Kabano A, Diaz T. IIffluence of community health volunteers on care seeking and treatment coverage for common childhood illnesses in the context of free health care in rural Sierra Leone'. Trop Med Int Health. 2014;19(12):1365-3156. doi:10.1111/tmi.12383.

\section{Submit your next manuscript to BioMed Central and we will help you at every step:}

- We accept pre-submission inquiries

- Our selector tool helps you to find the most relevant journal

- We provide round the clock customer support

- Convenient online submission

- Thorough peer review

- Inclusion in PubMed and all major indexing services

- Maximum visibility for your research

Submit your manuscript at www.biomedcentral.com/submit

C Biomed Central 